Artigos

\title{
MODOS DE COMUNICAÇÃO E APRENDIZAGEM DE LÍNGUAS NO SÉCULO XXI: DESAFIOS NA INTERNACIONALIZAÇÃO
}

\section{MODES OF COMMUNICATION AND LANGUAGE LEARNING IN THE $21^{\text {ST }}$ CENTURY: CHALLENGES FOR INTERNATIONALIZATION}

\author{
Marcelo Concário* \\ Maria Helena da Nóbrega** \\ Joaquim Coelho Ramos ${ }^{* *}$
}

\section{RESUMO}

As questões multiculturais e multilinguísticas são elementos essenciais na comunicação cotidiana em decorrência da crescente internacionalização. Dessa forma, ao mesmo tempo em que os espaços e as possibilidades para o uso autorizado das línguas maternas e estrangeiras tornam-se objetos de pesquisa e temas relevantes para cursos de formação de professores, as convenções de uso e a diversidade reafirmam sua importância nos processos comunicativos, e as competências linguístico-comunicativas consolidam-se como ferramentas inalienáveis na formação profissional. Este artigo avalia a complexidade desses novos contextos e como a aprendizagem de línguas dialoga com novas formas de saber, saber fazer, saber ser e saber aprender. Trata-se de um estudo exploratório, baseado nas experiências dos autores com ensino, pesquisa e gestão, e decorrente das reflexões suscitadas por nossas apresentações individuais no VII Simpósio Mundial de Estudos da Língua Portuguesa, realizado em agosto de 2019 em Porto de Galinhas, Pernambuco. O objetivo é problematizar a internacionalização em três âmbitos específicos, a saber: nos modos de comunicação destacados no Quadro Comum Europeu; no ensino de língua para fins específicos e nas políticas educacionais para o século XXI. Ao final da abordagem teórica, discute-se como a gestão de projetos pedagógicos relacionados à internacionalização - português para falantes de outras línguas ou outras línguas para falantes de português - pode contribuir para promover práticas responsivas às questões profissionais e educacionais do século XXI.

Palavras-chave: ensino de línguas; internacionalização; tecnologia.

* Universidade Estadual Paulista Júlio de Mesquita Filho , UNESP, Bauru, SP, Brasil. marcelo. concario@unesp.br Orcid: http://orcid.org/0000-0002-7051-7879

** Universidade de São Paulo, USP, São Paulo, SP, Brasil.mhn135@usp.br

Orcid: https://orcid.org/0000-0001-9300-0947

*** Instituto Português do Oriente, Macau. joaquim.ramos@ipor.org.mo

Orcid: https://orcid.org/0000-0002-1536-2544 


\begin{abstract}
Multicultural and multilingual issues are of central importance in everyday communication as a result of growing internationalization. Thus, as the places and possibilities for the authorized use of (first and foreign) languages become research objects and relevant topics in teacher education, conventions of use and diversity reaffirm their importance in communicative processes, and linguistic-communicative skills consolidate their value as inalienable assets in professional qualification. This paper addresses the complexity of this new scenario and how language learning relates to new ways of knowing something, knowing how to (learn to) do something, and knowing how to exist. It consists in an exploratory endeavor, based on the authors' experience as teachers, researchers and managers, which has been motivated by reflections on our individual presentations in the VII World Symposium on Portuguese Language Studies (VII Simpósio Mundial de Estudos da Lingua Portuguesa), which took place in Porto de Galinhas (Brazil) in August 2019. The objective is to look into internationalization in three specific domains, i.e.: the modes of communication highlighted in The Common European Framework of Reference (CEFR), the teaching of languages for specific purposes, and education policies for the 21 st century. Following the theoretical discussion, we attempt to demonstrate how the management of teaching policies related to internationalization Portuguese to speakers of other languages, or other languages to speakers of Portuguese can foster the development of practices in response to pressing professional and educational issues in the 21 st century.
\end{abstract}

Keywords: language education; internationalization; technology.

\title{
INTRODUÇÃO
}

O processo de internacionalização vem continuamente se consolidando no mundo globalizado, com reflexos em todos os setores, inclusive o educacional. Apesar de redirecionamentos abruptos no cenário político e econômico nas diferentes partes do mundo, dos obstáculos para a mobilidade e interação presencial decorrentes de uma crise sanitária para a qual nenhuma nação estava preparada e das incertezas relativas a quando e como tais barreiras serão contornadas ou eliminadas, não parece razoável supor que as ações de internacionalização serão abortadas. O que se espera, na verdade, é que se configurem novos cenários de interação mediada por recursos tecnológicos com grande impacto nos modos como utilizamos diferentes linguagens.

As mudanças sociais contemporâneas aceleram-se sobretudo a partir dos anos 1990, quando o uso da tecnologia passa a dominar diversos sistemas de produção e reconfigura praticamente todas as profissões. Como os setores técnicos dependem, em alguma instância, da educação formal, é importante avaliar de que forma as políticas educacionais têm se preparado para garantir a adaptabilidade do profissional do século XXI, que precisa saber lidar com instabilidade, competição mundial, inovação contínua, trabalho em equipe (LEITE, 1996), além de desenvolver 
capacidade de prever e solucionar problemas, proficiência multilíngue, habilidade de relacionamento interpessoal (PASTORE, 1998).

Do espaço físico aos ambientes digitais (MILL, 2009; RAMOS, 2009), das práticas pedagógicas à redefinição da matriz curricular, a certeza é que o conhecimento linguístico figura dentre as habilidades necessárias na internacionalização, tanto o domínio da língua materna como o de línguas estrangeiras.

Reconhecendo as questões linguísticas no cerne da internacionalização educacional, o propósito deste artigo é avaliar os modos de comunicação destacados no Quadro Comum Europeu, o ensino de línguas para fins específicos e as políticas educacionais para o século XXI. Nesse sentido, o texto aponta como o ensino de português para falantes de outras línguas ou de outras línguas para falantes de português pode promover práticas responsivas às questões profissionais e educacionais na atualidade.

Há um foco inicial no ensino profissionalizante ou superior, uma vez que grande parte das ações de internacionalização se implementam em universidades e centros de qualificação ou intercâmbio de adultos. Porém, a terceira seção do artigo dedica-se a políticas educacionais, com reflexões sobre os desafios que devem ser superados na preparação adequada dos alunos de modo mais abrangente.

A principal característica do Quadro Comum Europeu (CEFR), que orienta a análise e argumentação neste artigo, é a proposta dos quatro modos de utilizar a linguagem: recepção, produção, interação e mediação. Tais modos significam, de acordo com o CEFR (2018, p. 30), uma alternativa para "o modelo tradicional das quatro habilidades (ouvir, falar, ler, escrever), que cada vez mais se mostra inadequado para retratar a realidade complexa da comunicação".

No contexto das dinâmicas de internacionalização das línguas, a emergência do ensino para fins específicos acaba por acompanhar a evolução natural de uma cada vez maior intersecção de atividades humanas em contextos pan-geográficos, que acompanham a mobilidade crescente das pessoas. Não espanta, portanto, que a evolução científica e metodológica enquadrada pelo CEFR se verifique também nessa área da prática letiva. Não sendo necessariamente um fenômeno recente, o ensino de línguas para fins específicos tem se beneficiado dos avanços reconhecidos em áreas da Linguística Aplicada, como a análise textual. Isso acontece, sobretudo, pela estreita ligação entre a abordagem funcional inerente a mundos tecnicamente exigentes e a utilização massiva de documentos autênticos, com vista, as mais das vezes, a uma aplicação direta no mercado de trabalho, resultante da acima mencionada adaptabilidade profissional. 
Nas políticas educacionais, de modo geral, os resultados parciais apontam realizações inovadoras (MORAN, 2007; SOTO; MAYRINK; GREGOLIN, 2009) e aplicações ao ensino, bem como desafios que precisam ser enfrentados, como os critérios de avaliação e os materiais didáticos on-line (RAMOS, 2009). Sabe-se que colocar o aprendiz no centro de todo o processo de construção do conhecimento implica também atender às suas expectativas, motivações e exigências contextuais sendo certo que qualquer um de nós, aprendizes potenciais e efetivos de uma língua estrangeira, passa grande parte da sua vida útil em ambientes de interação laboral.

Com caráter exploratório, este texto investiga os modos de comunicação e a aprendizagem de línguas sob a influência da internacionalização. Comunicar, interagir e circular surgem, assim, como desígnios para o século XXI aos quais as línguas têm de saber dar resposta. Dessa forma, a pesquisa qualitativa observa e interpreta as formas de mediação linguística suscitadas pela tecnologia digital.

$\mathrm{O}$ artigo aborda um aspecto específico, de fundamentação, do quadro comum europeu, avaliando as implicações pedagógicas da sua utilização para a internacionalização do ensino. Depois disso, consideram-se as práticas da aprendizagem de línguas para fins específicos na internacionalização e, finalmente, os possíveis impactos no cenário educacional expandido no século XXI, com destaque para o incentivo ao uso da tecnologia nas políticas linguísticas. A conclusão traz à tona os desafios de formar adequadamente os alunos para os modos de produção resultantes da internacionalização e da presença crescente da tecnologia nas relações sociais e profissionais.

\section{OS QUATRO MODOS DE COMUNICAÇÃO NO QUADRO COMUM EUROPEU: CONSIDERAÇÕES SOBRE POSSÍVEIS IMPACTOS NO ENSINO E NA APRENDIZAGEM DE LÍNGUAS NA INTERNACIONALIZAÇÃO}

O potencial da avaliação para gerar mudanças no planejamento e na execução de ações de ensino, incluindo as características de materiais didáticos, é destacado na literatura especializada (ALMEIDA FILHO, 2013; 1993; SCARAMUCCI, 2004). No Brasil, entretanto, as políticas e os instrumentos de avaliação de proficiência em línguas não possuem a mesma tradição notada em vários outros países. Sobretudo em nações da Europa, critérios, testes e exames de proficiência vêm sendo estudados e aprimorados há tempos (www.alte.org; www.coe.int/lang-CEFR).

Esta seção tem como finalidade apresentar uma resenha crítica dos quatro modos de comunicação destacados no Quadro Comum Europeu (CEFR): recepção, produção, interação e mediação. Enquanto alternativa para o modelo das quatro 
habilidades de uso da linguagem, esses modos de comunicação destacam a interação e a mediação como componentes indispensáveis do saber linguístico-comunicativo. Documentos mais recentes relacionados ao CEFR (COUNCIL OF EUROPE, 2018) vêm explicitando, com mais clareza e detalhamento, competências a ser avaliadas (atingidas) no processo de aprendizagem de línguas, tais como a capacidade de (inter)agir na mediação linguística, na mediação cultural, na mediação social e na mediação pedagógica.

$\mathrm{O}$ acesso direto ao CEFR, ou a resenhas e trabalhos dedicados ao quadro, em língua portuguesa é limitado (cf. CANI; SANTIAGO, 2018; CONSELHO DA EUROPA, 2001). Essas duas publicações foram produzidas antes do lançamento do documento mais atual, em que se apoiam as reflexões apresentadas neste artigo. Cani e Santiago (2018) dedicam-se a analisar as implicações de descritores de competência em níveis avançados para a internacionalização em IES brasileiras, com foco na produção oral e escrita, e apontam a necessidade de adaptação desses descritores em razão dos seus objetivos. Apesar de haver coincidência dos termos internacionalização e CEFR, há diferença substancial ao comparar tal relato com o presente artigo: (1) como já foi observado, o texto de Cani e Santiago não faz referência à publicação mais recente do Conselho da Europa (COUNCIL OF EUROPE, 2018); (2) há duas ocorrências da palavra interação no trabalho de Cani e Santiago, sem qualquer relação explícita com o conceito de modo de comunicação, que configura tema central no presente artigo; (3) não ocorrem, em Cani e Santiago, tampouco os termos mediação ou modo de comunicação. O outro trabalho em língua portuguesa é a tradução do CEFR originalmente publicado em 2001, antes dos destaques dados a interação e mediação como vêm explicados a seguir.

Dando continuidade às ações do Conselho da Europa iniciadas em 1971 acerca de ensino, aprendizagem e avaliação de saberes linguísticos, o documento complementar ao CEFR original foi apresentado em fevereiro de 2018, após uma versão preliminar ter sido divulgada em setembro de 2017. O novo documento foi desenvolvido em diferentes fases e configura um complemento para o referencial anterior, publicado em 2001, o Ano Europeu das Línguas. A Aliança Francesa (especificamente a Aliança Francesa de Curitiba) e o Instituto Cervantes de Recife são as instituições no Brasil que figuram nos créditos na introdução do texto de 2018.

A elaboração desse documento mais recente deu-se nas seguintes fases: entre 2014-2015, foram preenchidas lacunas nas escalas de descritores de níveis de conhecimento; entre 2014-2016, foram criadas escalas que não existiam no original, principalmente quanto à mediação; entre 2015-2016, criou-se a escala para controle 
fonológico; entre 2015-2018, foram desenvolvidos descritores para linguagem de sinais; e entre 2014-2016, compilaram-se os descritores para aprendizes/usuários jovens (pré-adolescentes).

Na publicação original, o CEFR é apresentado como proposta de uma base de referência para a criação de conjuntos de conteúdos programáticos, orientações curriculares, avaliações, livros-texto e outros materiais, a ser compartilhada por toda a Europa. Segundo o CEFR (COUNCIL OF EUROPE, 2001, p. 10), o documento descreve detalhadamente o que deve ser aprendido para que usuários de línguas sejam capazes de comunicar-se e atuar com eficiência. Tal descrição contempla, ainda, contextos culturais de uso linguístico e níveis de proficiência para analisar e planejar a aprendizagem continuada de línguas.

Um princípio fundamental do CEFR é a formulação positiva de metas e objetivos educacionais para diferentes saberes linguísticos, com a caracterização de níveis de proficiência específicos por meio da explicitação do que um usuário será capaz de fazer na língua-alvo. Com isso, o CEFR tem a finalidade de promover e facilitar a cooperação entre diferentes instituições de ensino; estabelecer parâmetros confiáveis para reconhecimento mútuo de qualificações linguísticas; auxiliar no reconhecimento e na coordenação de esforços entre órgãos administrativos, avaliadores, gestores do ensino, professores e alunos.

Especificamente, o foco desta seção do artigo é chamar atenção para dois aspectos pontuais do CEFR: (1) a categorização dos descritores capaz de fazer em quatro bases macrofuncionais de atividades linguísticas (Recepção, Produção, Interação e Mediação) (COUNCIL OF EUROPE, 2001; 2018), e (2) que competências são enquadradas sob o item Mediação (COUNCIL OF EUROPE, 2018). Trata-se, portanto, de uma reflexão teórica, pautada em vivências de ensino e pesquisa em sala de aula, com a finalidade de apontar como o CEFR tem potencial para impactar em políticas, planejamento, implementação e avaliação de ensino especialmente relevantes para a internacionalização, assim como no ensino e na aprendizagem de línguas-culturas face a novas tecnologias e práticas de comunicação. Não se trata, entretanto, de assumir uma postura de mera aceitação do CEFR sem considerar o histórico da sua formulação nem o contexto para o qual vem sendo desenvolvido. Por outro lado, dada a atuação de inúmeros especialistas e organizações no aprimoramento dessa referência, destaca-se a importância de conhecê-la com propriedade, avaliar em que medida iniciativas locais podem ser pautadas em experiências internacionais e, possivelmente, contribuir para que todas sejam debatidas amadurecida e respeitosamente. 


\subsection{Escopo e terminologia no CEFR}

Não há descontinuidade nos conceitos que fundamentam o quadro comum. O termo competências gerais é empregado para referir-se a saber (conhecimento declarado), saber fazer (habilidades para realizar ações), saber ser e saber aprender (autorregulação, agência e condições de aprimoramento contínuo).

A competência linguístico-comunicativa, como componente de competência geral, refere-se aos saberes linguísticos, sociolinguísticos e pragmáticos. Por sua vez, o CEFR caracteriza atividades linguísticas como modos de usar a linguagem: recepção, produção, interação e mediação.

De modo geral, ao se compararem as publicações de 2001 e 2018 sobre o CEFR, nota-se um incremento relacionado à interação (COUNCIL OF EUROPE, 2018, p. 83-104), especificamente acerca da interação on-line, além de aspectos inéditos envolvendo a mediação (p. 105-131), linguagem de sinais (p. 148-158) e competência plurilinguística (p. 159-163).

No CEFR a interação é definida como processo em que pelo menos dois indivíduos participem em trocas orais ou escritas, com alternância entre produção e recepção, caracterizado pelo revezamento de turnos e cujo papel é central na comunicação. A mediação, por sua vez, é descrita - num primeiro momento - como aquilo que torna a comunicação possível entre pessoas incapazes de comunicar-se diretamente (COUNCIL OF EUROPE, 2001) e, mais tarde, é dado destaque à superação de obstáculos de qualquer natureza para a comunicação direta, incluindo o fato de os indivíduos serem falantes de línguas maternas distintas (COUNCIL OF EUROPE, 2018). A explicitação mais detalhada da mediação enquanto modo de usar a linguagem (atividade linguística) contempla, por exemplo, a mediação textual (repasse de informações específicas, explicação de dados, compartilhamento de como informações são processadas) em encontro (linguístico) pedagógico, cultural ou profissional.

Em razão do foco que se deseja dar à mediação neste artigo, é necessária uma explicitação mais minuciosa sobre o tema. Segundo o CEFR (COUNCIL OF EUROPE, 2018, p. 104), podem ser caracterizadas atividades de mediação e estratégias de mediação. Esses dois conjuntos configuram objetivos de aprendizagem no ensino de línguas.

As estratégias de mediação relacionam-se à: (1) explicação de conceitos novos (ações para estabelecer vínculos com conhecimentos prévios, identificação e sistematização de passos para alcançar informações mais complexas, e facilitação do insumo linguístico), e (2) simplificação textual (expansão para que um texto denso 
se torne mais apreensível na medida em que seja ajustada a sua informatividade/ aceitabilidade; e otimização do fluxo textual, com redução de ruídos).

Conforme citadas acima, as estratégias constituem modos de agir para viabilizar atividades de mediação. Tais atividades são categorizadas em: mediação de texto(s), mediação de conceito(s) e mediação da comunicação. A mediação de texto(s), como já mencionado anteriormente, relaciona-se ao repasse de informações (na fala ou escrita, podendo envolver tradução/interpretação; explicação de dados como gráficos, tabelas e diagramas; formulação de sínteses e realização de anotações, incluindo observações e reflexões críticas). Por sua vez, a mediação de conceito(s) pode envolver a facilitação de colaboração, e o incentivo à discussão e ao refinamento de conceitos e proposições, por meio de liderança e/ou resposta adequada para que haja interação eficaz em grupos de trabalho. A mediação da comunicação tem um foco mais específico na prevenção ou resolução de tensões relacionadas à linguagem (em vez de conteúdos), ou seja, relaciona-se - por exemplo - à facilitação em interações plurilinguísticas, à intermediação em encontros informais e a modos de lidar com situações delicadas em que possa haver divergências.

\subsection{Propostas para reflexão: CEFR, internacionalização, ensino- aprendizagem de línguas e Brasil}

No futuro, é possível que a categorização proposta no CEFR (recepção, produção, interação e mediação) favoreça práticas de ensino e ações de formação de professores que otimizem o uso de recursos - incluindo tempo - na medida em que sejam mais bem exploradas as semelhanças entre, por exemplo, fala e escrita acadêmica. Isso pode ser especialmente relevante nas práticas de linguagem tipificadas por monólogos, sem as trocas de turno que caracterizam outras situações comunicativas da vida cotidiana. De modo semelhante, se houver atenção específica para estratégias e atividades relacionadas à interação, podem ser favorecidas ações pedagógicas e reflexivas centradas no saber fazer (modos de agir) e saber ser/ aprender (identidade, agência, autonomia, autoconfiança) de alunos e professores - usuários de língua. Mais que isso, o foco na interação como modo/atividade de linguagem permitirá abordar e refletir sobre temáticas cada vez mais relevantes para encontros plurilinguísticos e multiculturais.

Segundo o CEFR, considera-se que a interação falada (entre pessoas) seja a origem da língua (COUNCIL OF EUROPE, 2018, p. 81), mas novos tempos nos levam a (re)avaliar os papéis da fala, do revezamento de turnos, das estratégias de colaboração e dos canais de interação. No Brasil, por exemplo, práticas corriqueiras 
ainda preservam espaços para interação tradicional - envolvendo pessoas físicas - nos caixas de supermercado, postos de combustíveis, em redes de restaurantes e lanchonetes, cabines de pedágio, bibliotecas etc. Nesse contexto, modos de interagir e mediar conservam práticas que podem, por um lado, ser associadas a gentileza, formas personalizadas e atenciosas no trato com aqueles com quem interagimos. Por outro lado, a preservação de modos de interagir e mediar que não sejam compatíveis com novos tempos e recursos tecnológicos podem se tornar antiquadas, morosas, burocráticas, redundantes e custosas, do ponto de vista mercadológico.

Muitos prestadores de serviço vêm abolindo o atendimento tradicional por telefone - ou mediado por pessoas em encontros face a face - em favor de novas tecnologias de interação, principalmente bate-papo virtual, por exemplo, com a troca de mensagens síncronas on-line e pelo aplicativo Whatsapp. Conceber a internacionalização como fenômeno crescente e irreversível implica reconhecer que a sociedade brasileira precisa estar mais preparada para lidar adequadamente com modos de comunicar que são mediados, cada vez mais, pelas tecnologias de informação e comunicação. Trata-se, portanto, de novos conhecimentos que devem integrar nossos repertórios de saberfazer e saber ser/aprender, os quais estarão diretamente ligados a novas configurações de competência linguístico-comunicativa: os modos de interagir e mediar exigidos nesses diferentes contextos.

Em outras palavras, as oportunidades e necessidades envolvendo interação online e tecnologias acabam colocando em uso - ou desuso - atividades e estratégias de interação fortemente determinadas pelo contexto e pelas práticas com que se esteja familiarizado. É natural que novos modos de interagir possam reforçar-mas também enfraquecer - alguns modos de usar a língua, e tais mudanças têm potencial para facilitar ou dificultar a comunicação plurilinguística e multicultural. Estar preparado para a internacionalização significa atualizar-se em contexto multicultural, o que inclui familiaridade com diferentes canais e modos de operacionalizar a linguagem na recepção, produção, interação e mediação.

As considerações relacionadas à tecnologia, cultura, ao saber fazer e saber ser/ aprender na linguagem claramente influenciam as estratégias e atividades de mediação. Um exemplo claro, quando levamos em conta o papel da tradução/interpretação, são os programas e recursos de tradução automática. Há diversos aplicativos que permitem o reconhecimento gráfico de texto de entrada/partida (incluindo ideogramas e outros tipos de escrita) e a emissão sonora desse original - ou já em outro idioma (texto de saída/chegada). Ter conhecimento dessas tecnologias, acesso a elas e saber como utilizá-las modificam as possibilidades de interação e mediação 
para usuários de línguas. Nesse cenário de possibilidades e oportunidades, fica claro que políticas de internacionalização e ensino de línguas (para a comunicação) envolvem a consideração cautelosa e visionária, além dos recursos suficientes, para que tais políticas não se tornem falsas promessas, ou fontes de frustração, em relação ao mito de que todos podem, naturalmente, ter acesso a tudo no mundo globalizado/internacionalizado.

Há outros aspectos relacionados à mediação no CEFR, menos desafiadores e extremamente promissores, que devem ser considerados. A versão mais recente do CEFR (COUNCIL OF EUROPE, 2018) fortalece ainda mais o potencial de o quadro comum europeu poder impactar positivamente na formação profissional em diversos setores. As estratégias de (mediação da) interação, por exemplo, constituem objetivos de aprendizagem que, por sua vez, podem levar ao aprimoramento progressivo de outras competências. Isso pode se concretizar por meio de oportunidades para que usuários/aprendizes exercitem papéis ativos, facilitadores de interações entre seus pares ou com professores. De modo mais específico, o CEFR - ao destacar as estratégias e atividades de mediação - explicita oportunidades para lidar com um problema recorrente na formação de professores (de línguas): de que forma monitorar e avaliar as suas competências gerais na língua (correção gramatical, conhecimento lexical) e as competências pedagógicas nos usos da língua (gestão de interação pedagógica, mediação na construção do conhecimento, adequação de metalinguagem).

\section{REFERENCIAIS E DIRETRIZES NA REALIDADE PROFISSIONAL DO SÉCULO XXI}

Uma das diversas dimensões em que o processo de internacionalização das competências linguísticas se manifesta aparece justamente no contexto do que se tem convencionado chamar a aprendizagem de língua para fins específicos. Tendo conhecido um incremento substancial a partir da década de 1960, impulsionada por uma globalização do comércio, pela celeridade e eficiência das comunicações e dos transportes num mundo globalmente em crescimento econômico, a dinâmica de ensino/aprendizagem de línguas sob uma perspectiva técnica, orientada para fins pré-determinados, mobilizou incontáveis aprendentes. A comunicação, agora aproveitada pelos mercados com fins assumidamente pragmáticos, tipifica-se nas décadas de 1970/80 como competência comunicativa, distinguindo-se do que acabaria por se designar capacidade comunicativa (WIDDOWSON, 1983): a primeira exigindo um domínio das convenções - por exemplo, gramaticais ou sociais; a segunda convocando um especial talento ou habilidade, mais ligado à criatividade. A 
conjugação desses elementos realizada pela mediação, agregando respectivamente as dimensões mais interpessoal e mais subjetiva do agente comunicativo, acaba por ser o objetivo último da otimização do resultado.

A dimensão pragmática e aplicada dessa abordagem emerge como o principal elemento diferenciador entre o ensino de uma língua estrangeira e o ensino de uma língua estrangeira para fins específicos. O transporte dessa premissa genérica para o contexto da língua portuguesa não parece afetar a veracidade da conclusão. $\mathrm{Na}$ verdade, como havia sido já descrito para outras línguas (v.g. STEVENS, 1988, apud DUDLEY-EVANS; ST. JOHN, 2011), o ensino de português para fins específicos centra-se em três momentos de referência: a identificação do contexto e das necessidades do grupo-alvo de aprendentes, as funções profissionais e tarefas por estes desempenhadas, e o papel que a linguagem desempenha no cumprimento dessas tarefas. A partir daqui, podem ser definidas as metas pedagógicas orientadas para um fim, englobando: 1) léxico específico; 2) estruturas de referência; 3) elementos discursivos próprios.

Ora, tal especificidade pode trazer para essa dinâmica elementos não cogitáveis sequer para a realidade de ensino-aprendizagem de uma língua estrangeira segundo uma abordagem comunicativista geral: pensemos, a título de mero exemplo, na diversidade lexical que se encontra no português econômico ou para negócios, com forte intersecção de estrangeirismos; na diversidade discursiva que se encontra no português jurídico, com alternatividade entre uma linguagem arcaica, formalista e altamente conservadora, e uma linguagem descritiva de fatos que prova ser atual e simples; ou na diversidade diastrática de um ensino do português para as áreas da náutica e da marinharia. Tem de haver nessa abordagem, portanto, uma ponderação metodológica exigente relativamente aos fatores envolvidos e determinantes do resultado: o domínio, por parte do aprendente e do professor - agora tido como mediador de aprendizagens, da área de especialização sobre a qual a linguagem incidirá; o domínio, por parte do professor-mediador, das realidades linguísticas associadas; a definição, por parte do aprendente, daquilo que são os seus interesses e que é exigido pela sua função na área de trabalho que desenvolve. É essa união de competências que garante o sucesso da dinâmica de aprendizagem, distribuindo também equitativamente pelos agentes a responsabilidade do processo.

Preparar a oferta de um curso de língua portuguesa para fins específicos, num contexto de internacionalização, confronta o docente com realidades decorrentes dos desafios metodológicos e conceituais que acabam de ser descritos. Tomemos a realidade dos manuais: a evolução dos processos técnicos da disciplina diagramática - por exemplo e a economia, a medicina, o direito ou qualquer outra no âmbito da 
qual se solicite o estudo de uma linguagem especializada - obriga a uma constante revisão dos manuais de língua para fins específicos, sob pena de se correr o risco de tratar aspectos técnicos desatualizados ou desacreditados pela evolução científica. O mesmo acontece, aliás, com o progresso notado nos aspectos pedagógicos e didáticos, cujas atualizações não podem deixar de ser consideradas nos materiais a disponibilizar. A interdisciplinaridade surge, assim, como ponto nuclear a considerar no processo, dada a exigência de uma banda alargada de conhecimentos que incluam as áreas de especialização acima mencionadas (ALARCÃO, 2008, p. 13), entre as que se dedicam à disciplina diagramática, as linguísticas e as ligadas às metodologias pedagógico-didáticas.

Inerente à dinâmica de ensino-aprendizagem de uma língua estrangeira para fins específicos, surge um outro elemento estruturante associado aos anteriormente elencados: a caracterização do público-alvo, das suas necessidades e dos elementos que, em contexto de turma, o compõem. Nesse campo, importa considerar a mais que provável heterogeneidade do grupo de aprendentes, nomeadamente em termos de origem profissional e aspirações, necessidades, orientação pragmática do curso e ritmos de aprendizagem. A articulação de todas essas variáveis com o núcleo teleológico fundamental do CEFR, enquanto instrumento modelador de uma abordagem essencialmente comunicativa, é fundamental no sucesso dos aprendentes e legitima a nova visão do ensinante enquanto facilitador de aprendizagens. Da mesma forma, o descritor de objetivos (MORROW, 2004, p. 7) e o caráter transcultural dos processos de facilitação/moderação e de aprendizagem incorporam, no CEFR tutelar do ensino de línguas para fins específicos, um significativo impacto de eficiência na criação de planos de ensino e na sistematização de abordagens pedagógicas (LITTLE, 2007, p. 648).

Aliás, um estudo (ATHANASIOU, 2016) sobre a relação entre a organização de cursos de língua para fins específicos - no caso centrado na língua inglesa, mas extrapolável para o português por obedecer a critérios de análise objetivos - no contexto do CEFR mostrou claramente que os responsáveis pela construção do plano de ensino (syllabus) seguem um de dois processos: ou começam pela avaliação das necessidades concretas dos aprendentes, ou pela ponderação dos descritores do CEFR, obtendo genericamente os mesmos resultados. Os descritores genéricos existentes foram ajustados ao conceito de descritores aplicados (ou disciplinespecific), com vista a responder às necessidades e expectativas dos aprendentes. Tais descritores, no entanto, deverão ser cuidadosamente tratados, na medida em que a sua validade ou neutralidade se encontra diretamente ligada à capacidade que tenham de orientar o facilitador/mediador para os objetivos linguísticos e de 
desempenho no contexto funcional que aguarda o aprendente; ou seja, um descritor aplicado, se demasiado rígido, transforma-se num descritor genérico, perdendo a valorimetria que possui para ser relevante no processo de obtenção de resultados, quer linguísticos, quer técnicos.

Essa dimensão de versatilidade é, aliás, em sintonia com o mercado de trabalho e com a realidade tendencialmente globalizante do emprego, caraterística das dinâmicas de ensino-aprendizagem de línguas para fins específicos especialmente enformadas pelas orientações metodológicas do CEFR. Daí a necessidade premente de trabalhar, não só sobre os conteúdos e as metodologias de ensino, mas também de explorar novos canais de intervenção educativa que permitam acompanhar a dimensão global do conhecimento e a mobilidade de agentes e de competências funcionais.

Os desafios que se apresentam de forma imediata podem, portanto, ser sistematizados em três grandes linhas de trabalho: 1) a formação teórica de base, cuja solidez deve ter em conta critérios formais estruturantes que permitam aos agentes educativos uma atualização permanente sem perderem a coerência do objeto de trabalho - no caso da língua portuguesa, um objeto pluricêntrico; 2) a dinâmica do ensino/aprendizagem em sala de aula multicultural, respondendo à crescente pressão da mobilidade e à necessidade de formar "cidadãos autónomos e críticos", facilitando o convívio entre "diversas culturas, a troca de experiências e de opiniões sobre diferentes formas de estar e de ser, sem estigmatizações nem marginalizações, a análise do agir humano, das suas intencionalidades e das suas formas" (BIZARRO, 2012, p. 120); 3) a adequação das políticas educacionais ao mercado de trabalho e às ferramentas tecnológicas disponíveis (e em constante expansão), sem determinismos pragmáticos unidirecionais que façam do mercado a única variável relevante para a construção de currículos, mas sem esquecer, por outro lado, a importância da aplicação de conhecimentos na prática diária, mormente num contexto internacional.

\section{POLÍTICAS EDUCACIONAIS PARA O SÉCULO XXI}

A complexidade dos novos contextos de mediação altera toda a cadeia produtiva e faz com que as habilidades e competências exigidas dos profissionais mudem, sobretudo quando essas alterações começaram a se acelerar, particularmente nos anos finais do século XX e início do XXI. Tais mudanças foram fortemente impulsionadas pela internacionalização, que, no caso das instituições educacionais, 
se concretiza no trânsito de professores, alunos e funcionários para promover a troca de conhecimento.

Como impacto da internacionalização, as novas tecnologias estão no sistema de produção da economia global, fazendo com que todos os cidadãos tenham que se adaptar às novas exigências sociais. Uma vez que a estrutura de mercado se encontra atravessada por novas formas de produzir, a automatização de tarefas rotineiras demanda maior nível de qualificação dos profissionais. Essas mudanças exigem uma nova concepção de escola, de forma a adequar a formação a esses cenários nos quais é importante saber aproveitar riscos e oportunidades.

As práticas de construção do conhecimento vêm sendo modificadas continuamente, principalmente com a irrupção abrupta da crise sanitária do início de 2020, que transformou as aulas presenciais em atividades remotas, síncronas ou assíncronas. $\mathrm{O}$ uso da tecnologia, então, teve que ser encarado pelos agentes educacionais: gestores, professores e alunos. A nova situação colocou a tecnologia digital no centro das atenções, com o risco de inverter a prioridade, ou seja, avançar no ensino digital antes de ajustar os parâmetros metodológicos.

$\mathrm{O}$ risco de transferir um modelo tradicional/expositivo de ensino para o contexto on-line comprometeria ainda mais os resultados educacionais. Em primeiro lugar, porque a aula expositiva, centrada na fala do professor, não utiliza os recursos tecnológicos disponíveis de interação e mediação (Slido, Mentimeter, Kaboot, apenas para citar alguns). Além de ser uma subutilização do ambiente virtual de aprendizagem, não facilita o desenvolvimento do saber fazer, saber ser e saber aprender, indispensáveis nos modos de comunicação da atualidade.

Dirigentes sociais, especialistas em educação e professores concordam que os projetos escolares precisam se renovar para atender às demandas vigentes (CORONADO; SAINZ; NAVAZO, 2009). Além do conteúdo técnico, é preciso abordar questões emocionais, relacionais e éticas. Ao mesmo tempo em que se valorizam práticas inter-relacionais, a autonomia também está em evidência. Essa formação, aliada à destreza com a tecnologia, deve garantir a preparação para enfrentar as incertezas do século XXI.

Portanto, as políticas educacionais precisam incentivar uma revisão integrativa dos conteúdos escolares para que os alunos estejam sendo formados para os desafios que encontrarão no mercado de trabalho, em qualquer área. Na mudança de requisitos exigidos dos profissionais do futuro, é possível detectar características gerais que serão úteis em vários setores, por exemplo, a habilidade de relacionamento interpessoal, sem perder o foco na tecnologia e nas ferramentas que vêm sendo utilizadas no ensino. Ao unir políticas educacionais e tecnologias, 
apontam-se caminhos que podem ajudar a acompanhar a rapidez das inovações sociais e tecnológicas nas propostas escolares.

Como exemplo dessa dissociação entre a escola e a vida profissional, vale lembrar os conteúdos estáveis e de pouca renovação que se observam em grande parte das disciplinas. As conceituações inabaláveis pouco dialogam com o mundo em permanente mutação da atualidade. Mais ainda, a solidez do conteúdo centraliza o ensino em técnicas de memorização, de pouca valia no cenário profissional internacionalizado, competitivo e inconstante.

A globalização alterou por completo as relações de mercado e, consequentemente, as qualificações dos trabalhadores. $\mathrm{Na}$ era da produção industrial, havia estabilidade e a competição ocorria localmente. A inovação, em passos lentos, surgia em etapas. Isso não significa que as mudanças eram aceitas imediatamente. Ao contrário, o padrão com relação a mudanças é elas provocarem rejeição inicial, quase como um instinto de preservação. No contexto industrial, o modelo de gestão estabelecia uma hierarquia vertical, controladora e punitiva (LEITE, 1996).

No novo paradigma, a constante instabilidade é reforçada pela competição mundial, e a inovação, andando em trem-bala, é contínua. Mal dá tempo de as pessoas se acostumarem a uma mudança e outra já é lançada, ditando necessidades antes impensadas. O modelo de gestão é mais participativo, com tomada de decisão horizontal e descentralizada, com viés orientador.

Essa forma de conceber os modelos produtivos altera os requisitos na qualificação. Em vez de obediência, espera-se iniciativa. O raciocínio substitui a memorização. A formação, antes programada para um período fixo, hoje deve ser continuada (LEITE, 1996).

Como muitas profissões são institucionalizadas no saber formal das escolas, os conteúdos programáticos têm que se adaptar rapidamente a essas mudanças de paradigmas. Além dos conteúdos, as práticas pedagógicas também precisam ser renovadas.

No que tange à forma de trabalhar os conteúdos, há indicações fortes de que as metodologias ativas de ensino trazem ganhos à aprendizagem dos alunos, estimulando o olhar crítico, o saber fazer, o saber ser e o saber aprender. Isso ocorre porque essas metodologias levam em conta o interesse do aprendiz, sua personalidade, seu ritmo e sua construção ativa do conhecimento. Disso decorre elevada autonomia e autoconfiança, fundamentais para o desempenho profissional de qualquer área. Ao incentivar a agência, as metodologias ativas parecem estar afinadas com as exigências do mercado atual, pois trabalham também "competências 
transversais [...], como, por exemplo, a capacidade de comunicação interpessoal e de trabalhar em grupo, a busca da autonomia, o espírito de iniciativa, de análise, de crítica construtiva e de síntese, entre outras" (COSTA et al., 2019, p. 79).

Para sedistanciardomodelo que atendia às necessidades da sociedadeindustrial, a escola precisa contextualizar os conteúdos e trabalhar a interdisciplinaridade, deixando de fora o viés segmentado que sustenta muitos projetos de ensino. Esse viés relacional entre diferentes conteúdos integra os saberes e incentiva o papel ativo do aluno.

Novas competências são esperadas dos jovens neste século XXI, o que aumenta o nível de exigência na formação, que evolui do conhecimento técnico para competências éticas e emocionais e habilidades tecnológicas.

O futuro exigirá profissionais competentes, multifuncionais, alertas curiosos que precisarão ter passado por uma educação que lhes tenha equipado com lógica de raciocínio; compreensão dos processos; capacidade de transferir conhecimentos; prontidão para antecipar e resolver problemas; conhecimentos de línguas; habilidade para tratar pessoas e trabalhar em equipe. Ou seja: um tipo de educação que dá às pessoas as condições de aprenderem continuamente.

(PASTORE, 1998, p. 28)

A escola, portanto, precisa de uma transformação pedagógica para formar profissionais com essas competências. Naturalmente, a inovação pedagógica não dispensa os investimentos que precisam ser feitos no contexto educacional brasileiro. A cultura digital precisa participar do currículo das escolas, pois ela é componente fundamental para acompanhar as inovações tecnológicas da sociedade.

\subsection{Letramento digital nas escolas}

Convém lembrar que as tecnologias não são novas na educação, sobretudo no ensino de línguas, que desde a década de 1960 se utiliza de laboratórios, gravadores de áudio, rádio e televisão.

As tecnologias transmissivas são exemplificadas pelo ensino por correspondência, que antecederam o e-learning, com suas técnicas interativas. Mais recentemente, tecnologias colaborativas vêm sendo desenvolvidas, de forma a gerar habilidades mistas nos estudantes.

Cada vez surgem mais ferramentas que viabilizam novas formas de comunicação: e-mails, lista de discussão, chats, blogs, programas de autoria, Whatsapp (RAMOS, 2009). Há ainda aplicativos para autoaprendizagem de línguas estrangeiras (Duolingo), sites de e-aulas, teleconferências, ou seja, a aprendizagem não está mais limitada à sala de aula. Muitos podem aprender de qualquer lugar e no momento que lhes for mais conveniente. 
A ubiquidade da aprendizagem é um aspecto desafiador para as escolas, pois os jovens sentem-se desmotivados ao ensino formal, sobretudo se ele não promove participação e autoria.

Nesse contexto que vêm se configurando nos últimos anos, a educação, de um modo geral, e a escola, mais especificamente, estão sendo convidadas a repensar suas propostas curriculares. Práticas pedagógicas diferenciadas estão sendo exigidas dos educadores atualmente. A associação entre a área educacional e tecnológica tornou-se o centro dos esforços pedagógicos para formação do cidadão. (MILL, 2009, p. 45)

Há projetos de inclusão das tecnologias educacionais em Portugal, Angola, Reino Unido, Chile, Finlândia, Suécia, Noruega e Dinamarca (PIMENTEL, 2018). No Brasil também já se destacou a necessidade de alfabetização digital, definida como

a aquisição de habilidades básicas para o uso de computadores e da internet, mas também que capacite as pessoas para a utilização dessas mídias em favor dos interesses e necessidades individuais e comunitários, com responsabilidade e senso de cidadania. (TAKAHASHI, 2000, p. 31)

O maior problema para o letramento digital está na infraestrutura, sobretudo se considerarmos a totalidade de escolas brasileiras. Há escolas em que a internet ainda é muito precária, o que inviabiliza projetos de currículos eletrônicos e materiais didáticos disponibilizados gratuitamente aos professores.

Os dados da velocidade também são constrangedores. Segundo o Cetic.br (2017), 3\% das escolas recebem $256 \mathrm{kbps}$, e apenas 16\% delas recebem 2Mbps, o máximo de velocidade ofertada, o que podemos considerar como muito baixa, considerando que muitas escolas apresentam número de alunos e turmas significativos, o que impediria o trabalho simultâneo com dispositivos móveis dentro de cada instituição. (CORDEIRO, BONILLA, 2018, p. 4)

De difícil superação, o entrave de acesso não tem impedido projetos que ajudam a vencer a inércia, como exemplo: Proinfo, Banda Larga nas Escolas, Um Computador por Aluno, Programa de Implantação de Salas de Recursos Multifuncionais, Programa Gesac (CORDEIRO, BONILLHA, 2018).

Como exemplo de investimento em tecnologia, temos o Currículo + , organizado pela Secretaria da Educação do Estado de São Paulo. O recurso pedagógico propõe uma articulação entre a tecnologia e o currículo escolar. Tratase de material inovador, mas nem sempre disponível em sala de aula, dadas as limitações já mencionadas na estrutura física das escolas, que muitas vezes possuem acesso limitado à internet.

Como problema a ser sanado, os pesquisadores apontam também a falta de coesão entre os projetos educacionais. 
Precisamos ressaltar que todos esses planos, programas, projetos e ações fazem parte de uma grande desarticulação em termos das políticas públicas brasileiras como um todo, e principalmente da educação. Nenhuma dessas iniciativas dialogam entre si, e parecem refletir uma esquizofrenia da máquina pública administrativa. (CORDEIRO; BONILLHA, 2018, p. 7-8)

Assim, as pesquisadoras apontam que as políticas de educação precisam descentralizar-se e desburocratizar-se, no plano administrativo, financeiro e pedagógico. Além disso, práticas engessadas em métodos tradicionais mantêm alguns agentes educacionais em sua zona de conforto:

[vários gestores de ensino público] conservam metodologias tradicionais e, em boa parte, barram as práticas educativas dos professores quando o assunto são tecnologias educacionais, até mesmo pelo fato de também não saberem lidar com a linguagem das TICs. (SOUSA, LIMA, 2018, p. 224)

De qualquer forma, não é uma boa escolha abrir mão da tecnologia nas práticas escolares, pois

[as] tecnologias são pontes que abrem a sala de aula para o mundo, que representam, medeiam o nosso conhecimento do mundo. São diferentes formas de representação da realidade, de forma mais abstrata ou concreta, mais estática ou dinâmica, mais linear ou paralela, mas todas elas, combinadas, integradas, possibilitam uma melhor apreensão da realidade e o desenvolvimento de todas as potencialidades do educando, dos diferentes tipos de inteligência, habilidades e atitudes. (MORAN, 2007, p. 164)

É possível, então, observar que as políticas linguísticas para o século XXI enfrentam realizações e desafios. Há dificuldades de ordem econômica, como a premência de abastecer as escolas com acesso irrestrito à internet. Ao lado dessas, há lacunas nos projetos pedagógicos, ainda pouco aderentes a ações que coloquem o aluno no centro do processo, que estimulem a recepção, produção, interação e mediação de modos comunicativos multiculturais e multilinguísticos.

\section{CONSIDERAÇÕES FINAIS E ENCAMINHAMENTOS}

Se - de fato - houver interesse em ações de internacionalização ligadas ao ensino de português para falantes de outras línguas, ou ao ensino de outras línguas para falantes de português (em especial, no Brasil), parece ser - cada vez mais necessário levar em conta as propostas e os desenvolvimentos relacionados aos modos de comunicação e à aprendizagem de línguas produzidos pela - e para a internacionalização. 
Os impactos do quadro comum europeu vêm sendo percebidos em diversos países fora daquele continente, sobretudo naqueles em que o inglês é a língua oficial/principal. Por isso, é natural que setores da Linguística Aplicada e Linguística Educacional sejam muito sensíveis aos empreendimentos do Conselho Europeu no ensino de línguas, dada a tradição e relevância da internacionalização em instituições de ensino europeias. Muitos materiais didáticos adotam os níveis de proficiência prescritos no CEFR para identificar a que tipo de usuário/aprendiz se destinam. Os níveis de proficiência e as competências caracterizadas pelas descrições do que o usuário é capaz de fazer vêm sendo usadas para explicitar equivalências entre exames internacionais adotados para aferir critérios de mobilidade estudantil, contratações de profissionais etc.

Observar os destaques aos modos de comunicar, em especial o maior detalhamento dado à interação e à mediação no CEFR, implica refletir sobre objetivos de aprendizagem em relação à linguagem de modo expandido. Não se trata de assumir que esse referencial seja inquestionável: o que se propõe, aqui, é que os esforços investidos na progressiva formulação do CEFR e a relativa escassez de referências em língua portuguesa justificam a expectativa de que este artigo possa estimular um debate mais amplo sobre saberes linguísticos e uma participação mais eficaz em ações de internacionalização nos domínios acadêmicos e profissionais.

Ainda é muito forte no Brasil a tradição de planejar ações pedagógicas com base nas quatro babilidades linguísticas, de modo isolado. Essa prática negligencia o CEFR e as semelhanças entre modos de ler e ouvir, por um lado, e de escrever e falar, por outro. Principalmente em contextos acadêmicos, ouvir e ler envolvem estratégias e competências muito semelhantes para a preparação e o acompanhamento dos encontros comunicativos de sala de aula, eventos especializados e reuniões de trabalho. Em situações envolvendo produção (fala e escrita), também se notam aspectos compartilhados entre as estratégias e competências de planejamento, execução, compensação e retificação nas atividades de linguagem das rotinas acadêmicas.

Em vez de prescrições baseadas em resultados empíricos específicos, as considerações compartilhadas neste artigo têm caráter de tópicos para reflexão, com base na experiência dos autores em pesquisa, ensino e na gestão de ações e projetos pedagógicos. Pode-se, a partir delas, reiterar a relevância do CEFR para reflexões sobre ensino e aprendizagem de línguas, formação de professores (de línguas, mas também de outras áreas), projetos e demais iniciativas de internacionalização considerando o contexto de mudanças viabilizado por tecnologias de informação e 
comunicação e, além disso, as diferenças culturais e contextuais que influenciam as atividades linguísticas.

No tocante ao processo de automação presente na sociedade contemporânea, o texto demonstrou como a tecnologia exige maior qualificação dos profissionais em praticamente todas as áreas. A passagem da industrialização para a era da informação altera as necessidades relativas ao saber, saber fazer, saber ser e saber aprender. A memorização, por exemplo, tem menor impacto na formação, e a resolução de problemas e adaptabilidade estão em evidências, pois as mudanças são rápidas e constantes.

Como resultado, tem-se que o conhecimento técnico em si não é mais suficiente. É preciso ir além, interagindo com a tecnologia, em todas as áreas.

Sendo papel da escola formar, desde cedo, os profissionais para a atuação em diferentes áreas, é necessário adaptar os conteúdos formais e as metodologias de ensino a tais necessidades, sobretudo no que diz respeito à inclusão das tecnologias.

A investigação das políticas públicas educacionais demonstra que há projetos para a renovação pedagógica e a incorporação de recursos digitais, mas eles esbarram na precariedade de acesso à internet.

O desafio, portanto, consiste em continuar trabalhando para vencer tais dificuldades, afinal, os novos profissionais têm que ser preparados para atuar no futuro, e não no passado. Embora seja cada vez mais incerto prever as profissões que permanecerão e as que surgirão, não parece arriscado dizer que a tecnologia digital veio para ficar, e que a sua presença na sala de aula é compulsória.

Dessa forma, a integração das TIC ao currículo representa, por um lado, a inclusão, a garantia do direito de seus alunos de participar da cultura digital, de suas linguagens, sentidos e formas de ler e de escrever o mundo. Incluir as tecnologias no currículo significa, por outro lado, valorar, atribuir significado pedagógico a todas as possibilidades emergentes com seu uso. (MONTEIRO, 2016, p. 3-4)

Os cursos de formação têm um papel preponderante na preparação dos professores, fornecendo condições de conhecimento e familiarização com a tecnologia para fins pedagógicos. Precisamos de formação também na criação de material didático digital que aproxime as experiências na escola das rotinas da vida real e supere o imobilismo presente em muitos projetos político-pedagógicos.

Em suma, além do letramento digital, é imprescindível ter como foco a mudança de paradigma no modelo de aula. O ensino encontra-se hoje fora dos domínios da sala de aula, basta ver a quantidade de cursos on-line disponibilizados na internet, muitos dos quais são grátis. A internacionalização rompe também com as fronteiras linguísticas e culturais. A questão da escola deve se voltar, portanto, 
para a aprendizagem, com ênfase na participação ativa do aluno no exercício dos diferentes modos de comunicação.

\section{REFERÊNCIAS}

ALARCÃO, I. (2008). Desafios atuais ao desenvolvimento da didática de línguas em Portugal. In: Bizarro, R. (Org.). Ensinar e aprender linguas e culturas boje: que perspetivas? Porto: Areal Editores, p. 10-14.

ALMEIDA FILHO, J. C. P. (1993). A operação global do ensino de línguas. In: Dimensões comunicativas no ensino de línguas. Campinas: Pontes, p. 17-24.

ALMEIDA FILHO, J. C. P. (2013). Dimensões comunicativas no ensino de linguas. Edição comemorativa, corrigida e ampliada. Campinas: Pontes.

ATHANASIOU, A. et al. (2016). Aligning ESP courses with the common European framework of reference for languages. In: Language learning in bigher education. v. 6, $\mathrm{n}^{\circ} 2$, p. 297-316. Disponível em: https://www.researchgate.net/publication/308940247 Aligning_ESP_courses_with_the_Common_European_Framework_of_Reference for_Languages. Acesso em 7 ago. 2019.

BIZARRO, R. (2012). Língua e cultura no ensino do PLE/PLS: reflexões e exemplos. In: Linguarum arena. v. 3, p. 117-131.

CANI, J. B.; SANTIAGO, M. E. V. (2018). O papel do quadro comum europeu de referência para idiomas: aprendizagem, ensino e avaliação (QCER) na internacionalização das IES: uma análise sob a perspectiva do Letramento Crítico e dos Multiletramentos. In: Trabalbos em Linguística Aplicada. v. 57, nº 2, p. 1164-1188.

CONSELHO DA EUROPA (2001). Quadro comum europen de referência para línguas: aprendizagem, ensino, avaliação. Edição portuguesa. Traduzido por Maria Joana Pimentel do Rosário e Nuno Verdial Soares. Porto: Edições Asa.

CORDEIRO, S. F. N.; BONILLA, M. H. S. (2018). Educação e tecnologias digitais: políticas públicas em debate. In: Anais do Senid. Universidade de Passo Fundo. Disponível em: https://www.upf.br/_uploads/-Conteudo/senid/2018-artigos-completos/178958. pdf. Acesso em 2 maio 2019 
CORONADO, M. L.; SAINZ, B.; NAVAZO, M. A. (2009). Nuevas tecnologías y su uso en educación. In: SOTO, U.; MAYRINK, M. F.; GREGOLIN, I. V. (Orgs.). Linguagem, educação e virtualidade. São Paulo: Cultura Acadêmica, p. 69-91.

COSTA, A. M.; OliveIRA, A. M.; REGO, B.; FIDALGO, S.; DELPLANCQ, V.; AMANTE, F. S.; RELVAS, S. (2019). Ensinar as línguas estrangeiras no ensino superior na era digital: uma experiência de inovação pedagógica. In: Millenium. v. 2 (ed especial), $\mathrm{n}^{\circ}$ 4, p. 75-80. Disponível em: https://repositorio.ipv.pt/ bitstream/10400.19/6208/1/14995-Article_Text-61248-1-10-20190607.pdf. Acesso em 5 ago. 2020.

COUNCIL OF EUROPE. (2001). Common European framework of references for languages: learning, teaching, assessment. Disponível em https://rm.coe.int/16802fc1bf. Acesso em 10 julho 2019.

COUNCIL OF EUROPE. (2018). New common European framework of reference for languages: learning, teaching, assessment. Companion volume with new descriptors. Disponível em https:// rm.coe.int/cefr-companion-volume-with-new-descriptors-2018/1680787989. Acesso em 10 julho 2019.

DUDLEY-EVANS, T.; STOHN, M. (2011). Developments in English for specific purposes: a multidisciplinary approach. 13. ed. Cambridge: Cambridge University Press.

LEITE, E. M. (1996). El rescate de calificación. Montevidéo: OIT.

LITTLE, D. (2007). Language learner autonomy: Some fundamental considerations revisited. In: Innovation in language learning and teaching. v. 1, nº 1, p. 14-29.

MILL, D. (2009). Educação virtual e virtualidade digital: trabalho pedagógico e educação a distância na idade mídia. In: SOTO, U.; MAYRINK, M. F.; GREGOLIN, I. V. (Orgs.). Linguagem, educação e virtualidade. São Paulo: Cultura Acadêmica, p. 29-52.

MONTEIRO, N. A. (2016). O que dizem as políticas educacionais sobre tecnologias para a educação? In: Anais Congresso Abed. São Paulo. maio/2016. Disponível em: http:// www.abed.org.br/congresso2016/traba-lhos/268.pdf Acesso em 2 maio 2019.

MORAN, J. (2007). As mídias na educação. In: Desafios na comunicação pessoal. 3. ed. São Paulo: Paulinas, 2007, p. 162-166. Disponível em: http://www.eca.usp.br/prof/moran/site/ textos/tecnologias_eduacacao/midias_educ.pdf. Acesso em 3 maio 2019.

MORROW, K. (Ed.) (2004). Insights from the common European framework. Oxford: Oxford University Press. 
PASTORE, J. (1998). A agonia do emprego. São Paulo: LTr.

PIMENTEL, F. S. C. (2018). Letramento digital na cultura digital: o que precisamos compreender. In: Revista EDaPECI. São Cristóvão. v. 18, nº 1, p. 7-16. Jan./abr. Disponível em: https://seer.ufs.br/index.php/edapeci/arti-cle/view/8545. Acesso em 2 maio 2019

RAMOS, R. C. G. (2009). Design de material didático on-line: reflexões. In: SOTO, U.; MAYRINK, M. F.; GREGOLIN, I. V. (Orgs.). Linguagem, educação e virtualidade. São Paulo: Cultura Acadêmica, p. 93-116.

SCARAMUCCI, M. V. R. (2004). Efeito retroativo da avaliação no ensino/aprendizagem de línguas: o estado da arte. In: Trabalhos em Linguística Aplicada. v. 43, n² 2, p. 203-226, Dec. Disponível em http://www.scielo.br/scielo.php?script $=$ sci arttext\&pid=S0103 $18132004000200002 \& \operatorname{lng}=$ en\&nrm=iso. Acesso em 10 julho 2019 (http://dx.doi. org/10.1590/S0103-18132004000200002).

SOTO, U.; MAYRINK, M. F.; GREGOLIN, I. V. (Orgs.) (2009). Linguagem, educação e virtualidade. São Paulo: Cultura Acadêmica.

SOUSA, H. F.; LIMA, F. R. (2018). Os desafios docentes e as contribuições das tecnologias educacionais no ensino e aprendizagem de língua inglesa: cenários contemporâneos. In: Revista EntreLínguas. Araraquara. v. 4, nº 2, jul./dez, p. 218-235. Disponível em: https://perio-dicos.fclar.unesp.br/entrelinguas/article/view/10969 Acesso em 4 maio 2019.

TAKAHASHI, T. (2000). Sociedade da informação no Brasil: livro verde. Brasília: Ministério da Ciência e Tecnologia. Disponível em: https://www.-governodigital.gov.br/ documentos-e-arquivos/livroverde.pdf. Acesso em 2 maio 2019.

WIDDOWSON, H. G. (1983). Learning purpose and language use. Oxford: Oxford University Press.

Recebido: $13 / 10 / 2019$

Aceito: $12 / 08 / 2020$

Publicado: 13/10/2020 